\title{
Farmer preferences and the production strategies of agroforestry nurseries in southeastern Madagas- car
}

Mark G. Downey' and Daniel deB. Richter'

\author{
Correspondence: \\ Mark G. Downey \\ Nicholas School of the Environment \\ Duke University, Box 90328, Durham, NC 27708, U.S.A. \\ E-mail: mark.downey@duke.edu
}

\begin{abstract}
Agroforestry projects in Madagascar that promote fruit trees address social and environmental threats to rainforests by reducing farmers' reliance on rice cultivation as long as fruit production is a more economically efficient option. This study aims to understand farmer planting preferences for fruit trees around Ranomafana National Park, specifically related to their ability to transport produce to wider markets. A large social survey assessed current fruit tree cultivation and the fruit planting preferences of farmers, and evaluated differences in farmer preferences based on distance to roads and markets. Survey results from 21 villages and 200 households indicate current fruit cultivation does not correspond well with planting preferences. Households near and far from roads share similar cultivation patterns and planting preferences with one exception: farmers living far from roads prefer to plant coffee significantly more than do those living near roads. This preference for coffee cultivation far from roads is attributed to coffee's relatively high sales price and ease of transport to buyers. This study also assesses current production in two local agroforestry nurseries and suggests new production priorities, notably focusing on coffee and lychee above the currently emphasized citrus fruits.
\end{abstract}

\section{RÉSUMÉ}

À Madagascar, les projets agroforestiers avec des arbres fruitiers peuvent représenter une réponse aux menaces sociales et environnementales qui pèsent sur les forêts naturelles en réduisant la dépendance des agriculteurs vis-à-vis de la riziculture pluviale à condition que la production de fruits constitue une option plus rentable. Les principaux obstacles à la production de fruits sur la périphérie du Parc National de Ranomafana sont le manque de connaissances des agriculteurs quant aux techniques de propagation, la rareté des espèces, variétés et cultivars d'arbres fruitiers qu'il conviendrait de planter ainsi que I'accès limité aux marchés avec des réseaux de transport fiables. Les organisations de développement de la région travaillent à la formation des agriculteurs et leur apportent les moyens initiaux requis pour démarrer des systèmes agroforestiers avec des arbres fruitiers. Cette étude vise à comprendre les préférences des agriculteurs lorsqu'ils plantent des arbres fruitiers à la périphérie du Parc National de Ranomafana et plus particulièrement par rapport à leurs moyens pour transporter leurs produits vers les plus grands marchés. Une importante enquête sociale a évalué l'état actuel de la culture des arbres fruitiers, les préférences des agriculteurs en matière de plantation pour les fruits à produire ainsi que les différences dans les préférences des agriculteurs en fonction de la distance aux routes et aux marchés. Le sondage réalisé auprès de 200 ménages dans 21 villages indique que la culture fruitière actuelle ne correspond guère aux préférences en matière de plantation. Les ménages résidant à proximité ou loin des routes partagent des modes de culture semblables ainsi que leurs préférences en matière de plantation à une exception près : les agriculteurs qui vivent loin des routes montrent une nette préférence pour la plantation de caféiers contrairement à ceux qui vivent à proximité des routes. Cette préférence pour la culture du café loin des routes est attribuée au prix de vente relativement élevé du café ainsi que de la facilité à le transporter vers les acheteurs. Cette étude a également procédé à une évaluation de la production de deux pépinières agroforestières locales et suggère de redéfinir les priorités en matière de production, notamment en mettant I'accent sur les plants de caféiers et de litchi plutôt que ceux des agrumes qui sont actuellement encouragés. II s'agit de I'enquête de la plus grande envergure qui ait été menée jusque là sur les préférences en matière de plantation d'arbres fruitiers à Madagascar, qui pourrait être reproduite à la fois sur la périphérie de Ranomafana et ailleurs pour aider les organisations de développement à améliorer leur soutien aux agriculteurs pour qu'ils se tournent vers la production de fruits plutôt que la culture du riz pluvial.

\section{INTRODUCTION}

Deforestation is a major threat to biodiversity and human populations in Madagascar's eastern rainforests. Of the 'original' 11.2 million hectares of rainforest extant at the island's colonization, 3.8 million hectares (about $34 \%$ ) were left by 1985; at the deforestation rates from the 1980's, Madagascar's rainforests will have vanished from all but the steepest slopes by 2025 (Green and Sussman 1990). Deforestation rates in eastern Madagascar slowed during the 1990 's, from $1.7 \%$ per year during the period 


\section{vOLUME 8 ISSUE 2

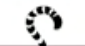 NOVEMBER 2013 MADAGASCAR 5,8 CONSERVATION \& DEVELOPMENT}

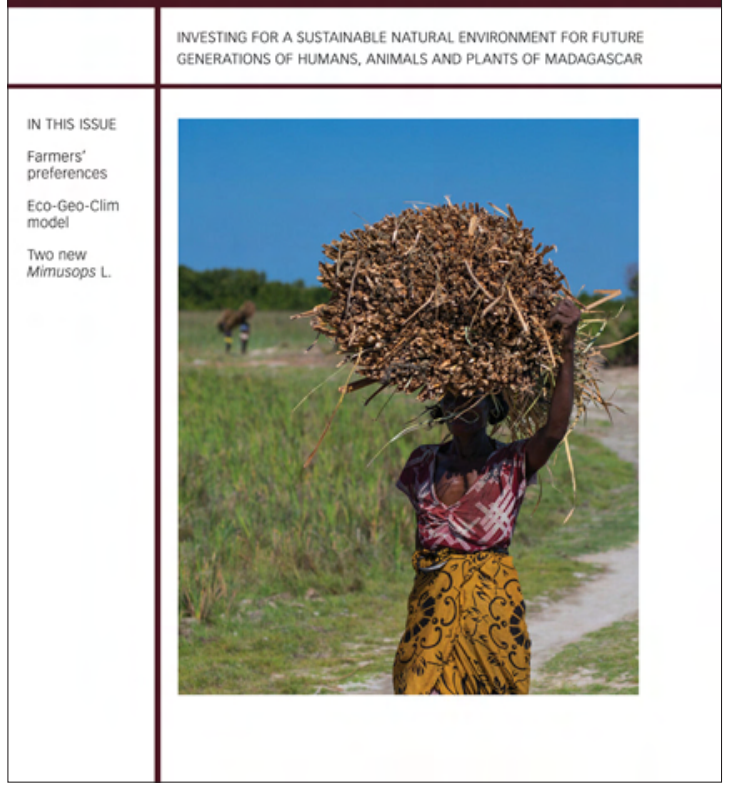

Madagascar Conservation \& Development is the journal of Indian Ocean e-Ink. It is produced under the responsibility of this institution. The views expressed in contributions to MCD are solely those of the authors and not those of the journal editors or the publisher.

All the Issues and articles are freely available at http://www.journalmcd.com

Contact Journal MCD

info@journalmcd.net for general inquiries regarding MCD funding@journalmcd.net to support the journal

Madagascar Conservation \& Development Institute and Museum of Anthropology University of Zurich

Winterthurerstrasse 190

$\mathrm{CH}-8057$ Zurich, Switzerland

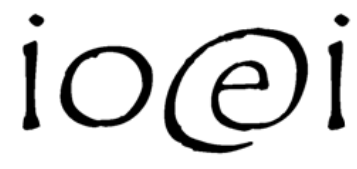

Indian Ocean e-Ink

Promoting African Publishing and Education www.ioeink.com
Missouri Botanical Garden (MBG)

Madagascar Research and Conservation Program BP 3391

Antananarivo, 101, Madagascar 
from the 1970 's to 1990 down to $0.8 \%$ per year from 1990 to 2000 (Harper et al 2007). Current forest cover lost is estimated to be about $0.45 \%$ per year (FAO 2010).

Though the ultimate causes of deforestation throughout the country are debated (Jarosz 1993, Peters 1999, Gezon and Freed 1999, Kull 2000, Nambena 2003, Holloway 2004, Styger et al. 2009), slash-and-burn farming, called tavy, is the prominent agricultural technology and leading cause of deforestation in the humid southeastern rainforests (Styger et al. 2007). In the tavy system, primary and secondary vegetation is cleared to make way for cultivation of staples such as rice, manioc, or sweet potato. After a series of short fallow periods and yearly cyclones, the deforested land quickly degrades (Nambena 2003, Styger et al 2009). The resulting loss of production requires farmers to cut and cultivate more forest, perpetuating the cycle (Randrianarijaona 1983, Kull 2000, Styger et al. 2007).

AGROFORESTRY. Fruit tree agroforestry systems address

immediate causes of deforestation in Madagascar by supplying sustainable income and nutrition to farmers without requiring land conversion (Green and Sussman 1990). In southeastern Madagascar near Ranomafana National Park (NP), these systems are usually mixed stands of native forest trees and exotic woody and non-woody fruit plants. The native trees are opportunistically involved to shade crops like coffee and vanilla, while most of the fruit trees are planted exotics (e.g., citrus, avocado, mango). These orchards' roots stabilize soils and increase infiltration; their canopies shield the soil from sun, wind, and rain; their litterfall replenishes the soil organic material (Young 1989).

Produce from these agroforestry orchards can comprise a substantial portion of farmer income, even enough for farmers to forego rice production, when farmers are able to transport the fruits to wider markets (Freudenberger and Freudenberger 2002, Nambena 2003). Around Ranomafana NP, these markets are most commonly accessible via intermediaries in trucks on the Route Nationale (RN) 45 or the small system of improved roads in the area. These intermediaries sell to vendors or juice manufacturers in the major cities. Thus, walking distances to improved roads and the transportability of different fruits likely impact species and cultivar compositions in agroforestry systems across the landscape.

Most exotic fruits grown in agroforestry systems around Ranomafana NP require specialized propagation techniques (e.g., grafting or air-layering) to efficiently produce marketable quantity and quality. Technical propagation training is rare around Ranomafana NP, and fruit quantity and diversity are limited as a result. Friends of Madagascar (FOM) is a non-profit organization promoting agroforestry projects around Ranomafana NP by providing technical fruit propagation training and boosting fruit supply and diversity in the area via nurseries. In 2010-2011, FOM established its own production nursery as well as one in collaboration with another local NGO, Centre ValBio (CVB). These nurseries grafted, layered, and otherwise prepared seedlings which were given to partnering farmer associations in order to stimulate their agroforestry systems and to provide desirable budstock from which the farmers could propagate their own additional trees. Initially, the nurseries propagated stocks opportunistically, based on what species and cultivars, and what propagation stock of each, were locally available. After one year of nursery operations, FOM sought to increase the diversity of fruit species and cultivars in the nurseries and to determine appropriate stocking ratios according to the preferences of farmers across its sphere of influence. We assessed current nursery production, conducted interviews to identify farmer preferences, and evaluated the role that farmer proximity to transport networks plays in cultivation and preference patterns.

\section{METHODS}

STUDY AREA. Ranomafana NP is a montane rainforest preserve in southeastern Madagascar. It covers 41,600 hectares on the highland's eastern escarpment. The park was established in 1991 after an undocumented lemur species, the golden bamboo lemur (Hapalemur aureus), was discovered in the area. As part of the Madagascar National Parks (MNP) system, Ranomafana NP restricts resource extraction (ANGAP 2003). These restrictions strain local populations who traditionally collected fuel and timber and practiced tavy in the forest. Resource use has since been intensified in the areas around the park. Beyond park boundaries, the landscape is almost entirely deforested, either planted with annual crops or fallowing. The two communes surveyed (Ranomafana and Kelilalina) sit directly east of the park boundary and are home to approximately 26,000 people (Ministère de l'Intérieur 2011). Route Nationale 45, the only paved road and the major commercial artery in the region, bisects the study area.

LOCAL AGROFORESTRY NURSERIES. Two agroforestry nurseries have been evaluated on the eastern side of Ranomafana NP. The first was established in 2010 and is located in the village of Mahatsinjorano in the Kelilalina Commune (S21 ${ }^{\circ}$

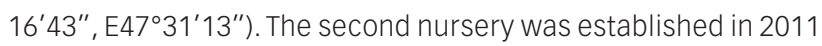
eight kilometers west in the town of Ranomafana, Ranomafana Commune $\left(\mathrm{S} 21^{\circ} 15^{\prime} 38^{\prime \prime}, \mathrm{E} 47^{\circ} 27^{\prime} 12^{\prime \prime}\right)$. Together these nurseries are capable of housing approximately 4,000 seedlings.

Both nurseries sit next to RN 45, but because the area beyond RN 45 lacks a reliable system of improved roads, seedlings must be transported from the pavement to farmers via footpaths. The growbags in which the seedlings are planted weigh 1-10 kg and must be handled gently during transport. Moreover, distribution anywhere south of RN 45 requires crossing the Namorana River, and no permanent bridges span it in either commune. Due to these factors, any village more than $2.5 \mathrm{~km}$ from RN 45 can be considered 'far' by the nurseries; in addition, these distance classes can be used to describe farmers' ease of transporting produce back to RN 45 (Figure 1).

SURVEY METHODS AND QUESTIONNAIRE DESIGN.

A social survey was conducted to investigate the current state of fruit cultivation as well as farmer preferences for future cultivation around Ranomafana NP. Local interviewers visited 21 villages within $7.5 \mathrm{~km}$ of improved roads on the eastern side of Ranomafana NP; given the difficulty of transporting seedlings beyond improved roads, this study area represents the likely sphere of influence of the two agroforestry nurseries. On average, between nine and ten participants were interviewed in each village, either in their homes or fields; 200 interviews were conducted in total. Participants were chosen by the village elder and split between males and females of three age classes: youth, adult, and elderly. The local interviewers helped in the design of a statement of informed consent to expressly and appropriately communicate to farmers that their participation in the study would not result in them receiving seedlings or 


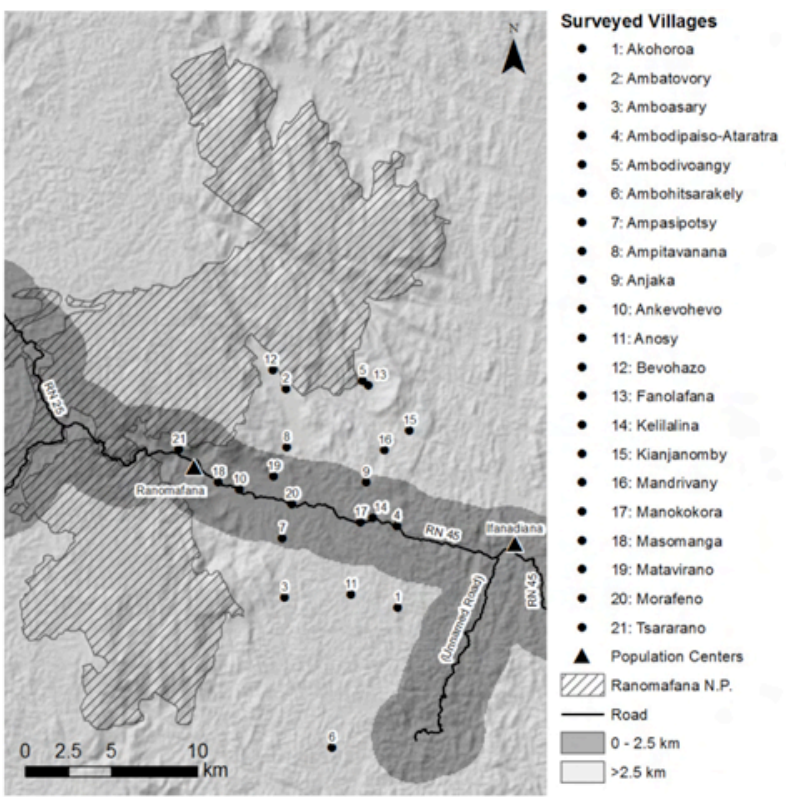

FIGURE 1. Study area and Ranomafana National Park, highlighting the surveyed villages and their Euclidean distances to roads; Projection: Geographic Coordinate System WGS 1984 (Ranomafana NP shapefile provided by Brian Gerber).

other benefits. Participants were read the statement of informed consent to which they responded with verbal agreement. The survey was conducted from February to April 2011.

Surveys were conducted in Malagasy through guided interviews following a questionnaire. The questionnaire had twenty multi-part questions; most questions had both open- and closed-ended elements as well as quantitative and qualitative elements. Interviewers transcribed answers to close-ended questions and recorded notes on answers to open-ended questions. Participants were asked, among other things, to list the fruits they cultivated, the number of stems they grew of each of those, and to quantify what is done with the harvested produce. They were also asked to rank their top five preferences for cultivating fruit trees and to explain those rankings. These preference rankings ranged from 5 to 1, descending from 5 as the "most preferred." For these questions, participants were free to list any plant they considered "fruit"; they were not provided with a multiple-choice set of fruit species and cultivars from which to choose. The number of stems grown was reported for the entire house, but preferences represented the participant's personal opinions. Interviewers then read several statements about satisfaction with local fruit cultivation, and participants indicated their level of agreement with those statements on a Likert scale (Likert 1932). The Likert scale ranged from 1 to 5 , with one representing "strongly agree" and five representing "strongly disagree".

SURVEY ANALYSIS. With the interviewers, the questionnaire responses were translated into English and compiled in Excel (Microsoft Office 2010). Average scores for the Likert scale questions were calculated. For current cultivation and planting preference numbers, only the top fifteen fruits grown and the top fifteen preferred to plant were considered; combined, this produced a list of seventeen fruits. The average number of stems grown per household was calculated based on the Borda Count election method (Black 1976) to determine the rank order of all fruits people preferred to plant. In this method, for a given fruit, the number of responses per rank was multiplied by the numerical value of the rank, and all were added up for a total 'Borda value'. Fruits not ranked were assigned an ordinal value of zero, and total Borda values for all fruits were corrected by dividing by the total number of respondents to estimate 'average ranks'. JMP 9.0 Pro (SAS 2012) was used to run Spearman's rank-correlation tests on stems planted versus planting preferences.

Differences in numbers of stems planted and fruit tree preferences between villages near and far from roads were examined. GoogleEarth (Google 2012) was used to digitize the improved roads in the study area, as well as the surveyed villages; these shapefiles were then exported to ArcMap 10. An Euclidean distance raster was created to delineate 'near' versus 'far' at $2.5 \mathrm{~km}$ from the road, for the transportation reasons mentioned previously. Ninety-eight participants resided near a road, and 102 were far, with the farthest being $7.5 \mathrm{~km}$ from a road. Spearman's rank-correlation tests were used to compare both the number of stems planted and planting preferences reported near and far from roads.

For the top five fruits most frequently grown per household, differences in distances from roads were tested with a one-way ANOVA. Differences between average planting preference ranks for farmers near and far from roads were then identified using the Mann-Whitney $\mathrm{U}$ test.

Finally, qualitative responses were grouped into categories such as 'economic', 'consumption', or 'medicinal' motivations for ranking a fruit; many responses fit into more than one category. Frequency tables were built within Excel for these response categories, both in total and delineated by distance from roads.

\section{RESULTS}

LIKERT SCALES. Averaged Likert scale scores strongly indicate that respondents i) are dissatisfied with the diversity of fruit they currently cultivate, ii) want to plant more fruit trees on their lands, and iii) want to plant new fruit species and cultivars.

CURRENT CULTIVATION VS. PLANTING PREFERENCES.

Spearman's rank-correlation test indicates that correlation between the average number of stems grown per household and the average ranked preference for each fruit is 0.102 . Spearman's rank-correlation test describes the degree of correlation between two variables, and it returns a statistic $(\rho)$ between -1 (a perfectly negatively correlated relationship) and +1 (a perfectly positively correlated relationship). The correlation between farmers' current cultivation patterns and their planting preferences is nearly perfectly non-existent (Figure 2, Table 1). Some fruits like banana and pineapple are planted at relatively high numbers yet are not highly preferred for additional planting. Coffee, though, is planted at relatively high numbers but it is also highly preferred for planting. Other fruits such as lychee and mandarin are not cultivated much but are highly desired for planting. Many fruits, like mango, are neither planted much nor highly preferred in the study area.

DISTANCE TO ROADS. The average numbers of stems grown per household are strongly positively correlated ( $\rho=0.966, p=<0.0001$ ) between communities near and far from roads (Figure 3 ). The correlation places each fruit very close to a 1-1 line, indicating that the relationship is not only monotonic but also nearly equivalent. However, most points lie 


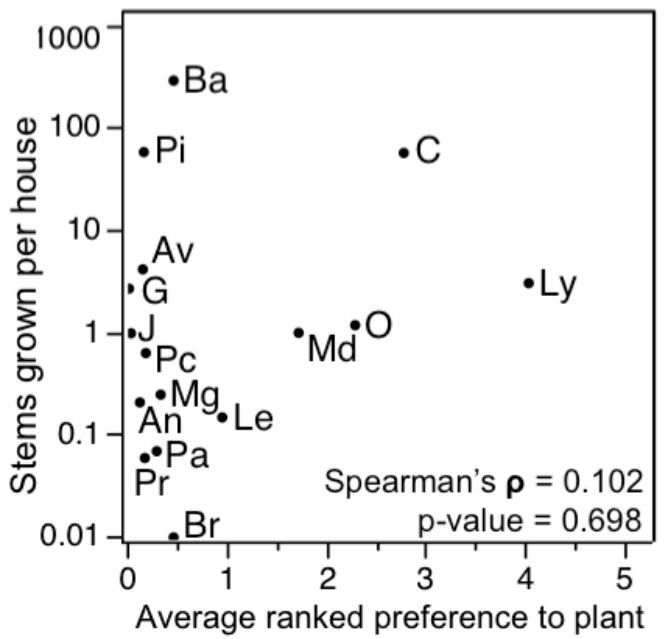

FIGURE 2. Spearman's rank-correlation test between the average number of stems of each fruit grown per household and the average ranked preference to plant each of those fruits, showing no significant correlation. Banana (Ba), Pineapple (Pi), Coffee (C), Avocado (Av), Lychee (Ly), Guava (G), Orange (O), Mandarin (Md), Jackfruit (J), Peach (PC), Mango (Mg), Annona (An), Lemon (Le), Papaya (Pa), Persimmon (Pr), Breadfruit (Br), Apple (Ap)

above the 1-1 line, suggesting that these fruits are cultivated in higher quantities on farms near roads. Banana is grown significantly more in villages near the road $(p=0.015)$, and the same is true for lychee $(p=0.0003)$. In addition to those two, pineapple, coffee, and avocado comprise the top five most cultivated fruits in both distance classes, but there are no significant differences in cultivation numbers for these latter three fruits.

The average preferences to plant each fruit are also strongly positively correlated between farmers near and far from roads (Figure 4). The high (0.914) indicates that farmers near and far from roads have similar planting preferences; indeed, the top five fruits preferred to plant are the same for each distance class. Again, this relationship sits very close to the 1-1 line. The

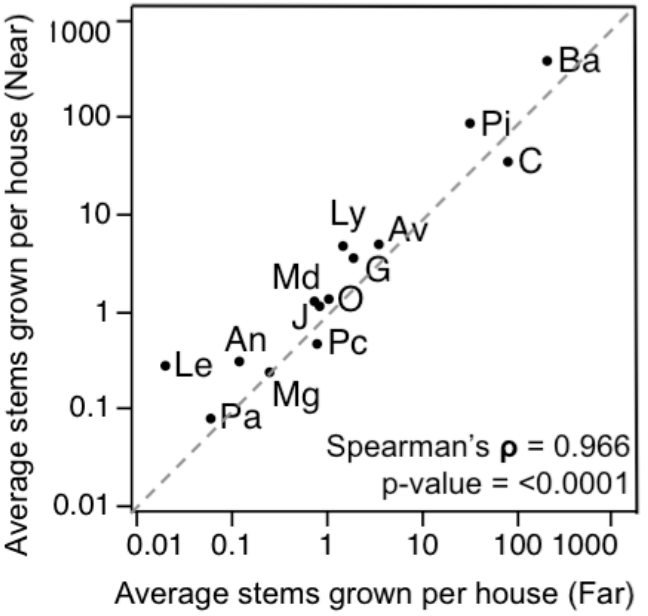

FIGURE 3. Spearman's rank-correlation test between cultivation patterns near and far from roads, showing significant positive correlation between the average number of stems of each fruit grown near and far from roads. Abbreviations as in Figure 2.

notable exception is for coffee, which farmers far from roads preferred to plant at similar levels to lychee. The Mann-Whitney $\mathrm{U}$ test for independence indicates that farmers far from roads report significantly higher preferences for planting coffee than do farmers near roads $(p=0.003)$.

QUALITATIVE ANALYSIS. Analysis of the qualitative

data associated with planting preferences may illuminate the correlations in current cultivation and planting preferences near and far from roads (Table 2). For all of the top five fruits, farmers far from roads mentioned 'consumption' motivations for preferring to grow a fruit more than farmers near roads, and farmers near roads mentioned 'economic' motivations for preferring to grow a fruit more than farmers far from roads. Both distance classes mentioned 'future security' motivations at identical rates for preferring bananas. They also had similar

TABLE 1. Comparison of the average number of stems grown per household (SH), the average ranked preference (RP), and the relative rank order (RRO) for each fruit for all respondents, subdivided for respondents 'near' and 'far' from roads.

\begin{tabular}{|c|c|c|c|c|c|c|c|c|c|}
\hline \multirow[b]{3}{*}{ Fruit } & \multirow{2}{*}{\multicolumn{3}{|c|}{ number of stem per household }} & \multicolumn{6}{|c|}{ ranked preference } \\
\hline & & & & \multicolumn{3}{|c|}{ average } & \multicolumn{3}{|c|}{ relative } \\
\hline & total & near & far & total & near & far & total & near & far \\
\hline Banana & 295.4 & 386.4 & 208.0 & 0.5 & 0.6 & 0.3 & 6.5 & 6.0 & 10.0 \\
\hline Pineapple & 59.4 & 87.9 & 32.1 & 0.2 & 0.1 & 0.2 & 13.0 & 15.0 & 11.0 \\
\hline Coffee & 58.3 & 35.3 & 80.5 & 2.8 & 2.0 & 3.6 & 2.0 & 3.0 & 2.0 \\
\hline Avocado & 4.2 & 5.0 & 3.5 & 0.1 & 0.1 & 0.1 & 14.0 & 13.0 & 12.0 \\
\hline Lychee & 3.1 & 4.8 & 1.5 & 4.0 & 4.1 & 4.0 & 1.0 & 1.0 & 1.0 \\
\hline Guava & 2.7 & 3.6 & 1.9 & 0.0 & 0.0 & 0.0 & 17.0 & 17.0 & 17.0 \\
\hline Orange & 1.2 & 1.4 & 1.1 & 2.3 & 2.5 & 2.1 & 3.0 & 2.0 & 3.0 \\
\hline Mandarin & 1.0 & 1.3 & 0.7 & 1.7 & 1.9 & 1.5 & 4.0 & 4.0 & 4.0 \\
\hline Jackfruit & 1.0 & 1.2 & 0.8 & 0.0 & 0.0 & 0.0 & 16.0 & 16.0 & 16.0 \\
\hline Peach & 0.6 & 0.5 & 0.8 & 0.2 & 0.2 & 0.1 & 11.0 & 10.0 & 14.0 \\
\hline Mango & 0.3 & 0.2 & 0.3 & 0.3 & 0.2 & 0.4 & 8.0 & 11.0 & 7.0 \\
\hline Annona & 0.2 & 0.3 & 0.1 & 0.1 & 0.1 & 0.1 & 15.0 & 14.0 & 15.0 \\
\hline Lemon & 0.2 & 0.3 & 0.0 & 0.9 & 1.3 & 0.6 & 5.0 & 5.0 & 5.0 \\
\hline Papaya & 0.1 & 0.1 & 0.1 & 0.3 & 0.2 & 0.3 & 10.0 & 9.0 & 9.0 \\
\hline Persimmon & 0.1 & 0.1 & 0.0 & 0.2 & 0.2 & 0.1 & 12.0 & 12.0 & 13.0 \\
\hline Breadfruit & 0.0 & 0.0 & 0.0 & 0.5 & 0.4 & 0.5 & 6.5 & 7.0 & 6.0 \\
\hline Apple & 0.0 & 0.0 & 0.0 & 0.3 & 0.3 & 0.4 & 9.0 & 8.0 & 8.0 \\
\hline
\end{tabular}




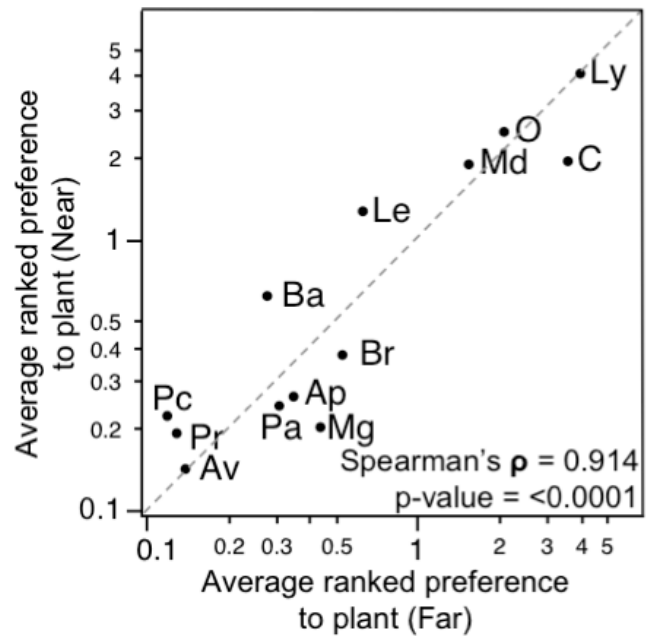

FIGURE 4. Spearman's rank-correlation test between planting preferences near and far from roads, showing significant positive correlation between the average ranked preferences to plant each fruit near and far from roads. Abbreviations as in Figure 2.

rates of citing 'medicinal' motivations for preferring to grow lemons. When asked which fruits they would prefer to sell, only farmers far from roads mentioned 'transportation' motivations, and the fruit most frequently preferred for 'transportation' motivations was coffee.

\section{DISCUSSION}

Freudenberger and Freudenberger (2002) have documented that farmers in the study area are willing to forego rice cultivation - and the implicit tavy associated with upland rice cultivation - and instead purchase rice with revenues from fruit as long as they have access to wider markets. However, lacking access to such markets, these farmers may redouble their efforts at subsistence crop production, risking further environmental degradation. Respondents in our study demonstrated that access to wider markets broadened their economic opportunities: farmers near roads were more likely to mention 'economic' motivations for ranking their fruit planting preferences, and farmers far from roads were more likely to mention 'consumption' motivations.

It is not only farmers' physical access to markets but also their supply of valuable, transportable fruits that allows them to forgo upland rice cultivation. Styger et al. (1999) reported that farmers in villages near Ranomafana NP but far from roads might be able to profit from indigenous fruits if they had easier access to markets, if the fruits kept better, and if they could get better prices for the fruits. As a result, indigenous fruits are not currently commercialized, or else done so at a minute scale for low prices. Indeed, respondents in our study, when considering which fruits they would prefer to cultivate and sell, did not mention indigenous fruits; the top ten most preferred fruits on our list of production priorities are exotic species. Both studies, then, suggest that indigenous fruits are currently unlikely to provide enough income for farmers to forgo rice cultivation. Therefore, focusing on indigenous fruits could waste time and resources in agroforestry projects intending to supplant tavy. Moreover, if farmers in the region are able to consistently produce desirable, exotic fruit crops, local governments might be incentivized to create and maintain more effective systems of roads into the deforested countryside. Such a transport network could support a permanent focus on fruit production, and even facilitate indigenous fruit commercialization as well.

Development organizations focusing on agroforestry projects around Ranomafana NP must find ways to ensure that fruit production is as attractive as possible, especially in the face of difficult transportation. Aside from building roads, then, this involves aligning seedling production in the agroforestry nurseries with farmer planting preferences. Those preferences theoretically reflect the farmers' appreciation of the economic and nutritional values of fruits. Therefore, producing and planting fruit trees according to farmer preferences will help ensure that the trees have the greatest chance of receiving care from the farmers and thus surviving to sustain farmers' livelihoods.

At the time of this survey, nursery stocks were not aligned well with farmer planting preferences. Respondents across the study strongly indicated that they are dissatisfied with both the quantities and diversity of fruit they currently cultivate, and that they are interested in planting more fruit. In addition, in the qualitative responses associated with the Likert questions about satisfaction, respondents commonly assured interviewers that they had open, unused land on which to plant fruit trees. These responses highlight local demand for nursery products and support the expansion of species and cultivars currently stocked in the nurseries. However, since there is no correlation between the fruits farmers currently cultivate and those they would prefer to cultivate, the roles of agroforestry nurseries are more complicated than merely filling gaps between cultivation and preferences.

Cultivation patterns and planting preferences are similar throughout the study area, which means that a single, appropriately stocked nursery can supply any project in the area regardless of distance to roads. But, the dissimilarities related to geography are just as important to consider for properly equipping farmers to choose fruit production over upland rice cultivation.

Farmers near roads are less interested in the difficulty of transporting their fruits, possibly because they have easy access to the intermediary collection trucks on the roads. Significantly more bananas ( $p=0.015)$ and lychees $(p=0.0003)$ are grown near roads than far from roads. Both bananas and lychees are sold at high weight to price ratios, which means that they may not be as profitable for countryside farmers to transport over the hills to the road.

Conversely, coffee is preferred to plant significantly more by farmers far from roads than by those near roads, a difference we attribute to coffee's transport efficiency. In response to the survey question "List the top five fruits you would prefer to sell, in order of preference...", only farmers far from roads mentioned "transportation" as a consideration when selling fruit, primarily coffee. Coffee beans are small fruits with disproportionally high market prices. In comparison, a stalk of bananas, which weighs about $20 \mathrm{~kg}$, would fetch the same price as $2.5 \mathrm{~kg}$ of coffee at the time of this study. Over difficult mountain footpaths, transporting coffee makes more economic sense than heavy, relatively cheap fruits like bananas. Fruits like coffee allow farmers far from roads to most efficiently engage wider markets.

There are other considerations beyond transport efficiency that influence local fruit cultivation. Lemons and bananas, for example, filled specific niches throughout the study area. Lemons were preferred for their natural medicinal qualities. 
TABLE 2. Response rates (\%) for different categorical motivations for preferring to plant the top five favorite fruits. Categorical motivations: consumption (Co), economic (EC), current low quantity (CLQ), flavor (FI), transportation (Tr), productivity (Pr), land improvement (LI), medicine (Me), future security (FS), other (Ot); distance classes (DC): $n=$ near, $\mathrm{f}=\mathrm{far}, \mathrm{t}=$ total.

\begin{tabular}{|c|c|c|c|c|c|c|}
\hline \multirow[b]{2}{*}{ Categorical Motivation (\%) } & \multirow[b]{2}{*}{ Distance } & \multicolumn{5}{|c|}{ Fruits } \\
\hline & & Lychee & Coffee & Orange & Mandarin & Lemon \\
\hline \multirow{3}{*}{ Consumption } & near & 33.3 & 56.5 & 33.3 & 38.3 & 29.3 \\
\hline & far & 48.5 & 66.7 & 56.2 & 52.5 & 30.8 \\
\hline & total & 41.2 & 63.1 & 44.6 & 45.4 & 29.9 \\
\hline \multirow{3}{*}{ Economic } & near & 94.6 & 78.3 & 85.3 & 93.3 & 97.6 \\
\hline & far & 90.9 & 72.6 & 78.1 & 86.4 & 73.1 \\
\hline & total & 92.7 & 74.6 & 81.8 & 89.9 & 88.1 \\
\hline \multirow{3}{*}{ Current low quantity } & near & 9.7 & 10.9 & 16.0 & 18.3 & 4.9 \\
\hline & far & 10.1 & 6.0 & 11.0 & 8.5 & 0.0 \\
\hline & total & 9.9 & 7.7 & 13.5 & 13.5 & 3.0 \\
\hline \multirow{3}{*}{ Flavor } & near & 10.8 & -- & 9.3 & 6.7 & 2.4 \\
\hline & far & 16.2 & -- & 8.2 & 3.4 & 0.0 \\
\hline & total & 13.5 & -- & 8.8 & 5.0 & 1.5 \\
\hline \multirow{3}{*}{ Transportation } & near & 1.1 & 0.0 & 0.0 & 0.0 & -- \\
\hline & far & 2.0 & 10.7 & 2.7 & 1.7 & -- \\
\hline & total & 1.6 & 6.9 & 1.4 & 0.8 & -- \\
\hline \multirow{3}{*}{ Productivity } & near & 5.4 & 6.5 & 5.3 & 10.0 & 4.9 \\
\hline & far & 2.0 & 0.0 & 1.4 & 6.8 & 3.9 \\
\hline & total & 3.7 & 2.3 & 3.4 & 8.4 & 4.5 \\
\hline \multirow{3}{*}{ Land improvement } & near & 1.1 & 4.4 & -- & -- & -- \\
\hline & far & 0.0 & 2.4 & -- & -- & -- \\
\hline & total & 0.5 & 3.1 & -- & -- & -- \\
\hline \multirow{3}{*}{ Medicine } & near & -- & -- & 1.3 & 0.0 & 29.3 \\
\hline & far & -- & -- & 0.0 & 3.4 & 26.9 \\
\hline & total & -- & -- & 0.7 & 1.7 & 28.4 \\
\hline \multirow{3}{*}{ Future security } & near & -- & -- & -- & -- & -- \\
\hline & far & -- & -- & -- & -- & -- \\
\hline & total & -- & -- & -- & -- & -- \\
\hline \multirow{3}{*}{ Other } & near & 1.1 & 8.7 & -- & -- & -- \\
\hline & far & 4.0 & 4.8 & -- & -- & -- \\
\hline & total & 2.6 & 6.2 & -- & -- & -- \\
\hline \multirow{3}{*}{ Sample Size N } & near & 93 & 46 & 75 & 60 & 41 \\
\hline & far & 99 & 84 & 73 & 59 & 26 \\
\hline & total & 192 & 130 & 148 & 119 & 67 \\
\hline
\end{tabular}

Bananas have no definite growing season and can be harvested and sold year-round, unlike most other fruits. Thus, bananas were commonly mentioned across the study area as sources of money in emergency situations, adding to a family's financial stability. Moreover, the top five fruits most preferred to plant were preferred primarily for 'economic' motivations but 'consumption' motivations were also strongly present, indicating that these fruits can play a role in supplanting farmers' reliance on the cultivation of subsistence crops.

We have presented a unified list of suggested priorities for agroforestry nurseries around Ranomafana NP (without banana, which does not need to be propagated in nurseries). While the same fruit species and cultivars can be planted in any agroforestry project in the study area, our recommendations do not necessarily translate to fixed production ratios. It will remain for nurseries to decide how many seedlings of each fruit to propagate, based on the expected yields and values of the different fruits, as well as the given project's distance to a road. For example, coffee ought to be prioritized in agroforestry projects far from roads, based on its high preference by remote farmers as well as its conservation and economic value: coffee production requires an overstory for shade, which encourages the protection of native stands; coffee stumps re-sprout after being cut, which discourages yearly burning; and in the study area, coffee's high transport efficiency makes it an economically valuable fruit for remote farmers to produce. As the nurseries decide production ratios of the prioritized fruits, however, diversification must be stressed; what is currently preferred and economically beneficial may change by the time a project's seedlings are producing crops.

Because farmers' preferences are subject to change, it is vital that agroforestry project managers continue to track those preferences. At the time of this publication, Styger et al.'s (1999) study is the only other social survey focused primarily on farmers' fruit preferences in Madagascar. They interviewed twenty-four participants in two villages far from roads in the 
Ranomafana Commune and nearer Ranomafana NP's primary forest. The researchers were focused on villager preferences for indigenous fruits and the potential for those fruits to be consumed or commercialized as part of agroforestry systems in the area. Our study built on Styger et al.'s (1999) work in Ranomafana by replicating their demographic cross-section; collecting a larger sample size (200 respondents); allowing farmers to state preferences for any fruit, indigenous or exotic; and interviewing farmers both near and far from roads in order to make prescriptions for the development organizations based near roads but working across the landscape. The scale of our study provides a current and reliable cross-section of fruit growers around Ranomafana NP from which agroforestry project managers can begin to base their production and outreach strategies. The major weakness of this investigation, which ought to be addressed in follow-up studies, is that our survey was conducted in one three-month window. This may have allowed a temporal bias into the preferences we recorded, specifically related to the economic trends in fruit prices at the time of the survey, instead of capturing the possible fluctuations in fruit popularity over the course of a year. We attempted to buffer the effects of such a bias with a large sample size. However, since the top two most preferred fruits were out of season at the time of the survey, it appears that such a bias did not considerably affect our findings.

Future work will involve increasing the diversity of cultivars of each fruit grown in the nurseries and continuing to train farmers to propagate their own seedlings. The cultivars currently grown in the study area (including the nurseries) are not necessarily those best suited to the environment or human needs. since different cultivars often do not bear fruit at the same times, increasing cultivar diversity allows farmers to experience longer growing and harvesting seasons, thereby avoiding low prices in saturated markets.

Moreover, while satisfying farmer preferences increases buy-in for agroforestry systems, it is important to note that those preferences are based on their imperfect knowledge of available fruit species and cultivars, and there is room to influence future preferences. For example, neither avocado nor mango is highly desired in the study area, but this might be a reflection on the local cultivars of each, not the species themselves. Mangos around Ranomafana NP are usually susceptible to anthracnose, causing them to mature slowly and produce poorly, but a hardier and more palatable cultivar may interest local farmers. The avocados in the study area are small, bland, and rot quickly on trees, but cultivars exist elsewhere in the world that could produce more desirable fruits.

Development organizations, Malagasy university researchers, and local and national governments all share the responsibility of building farmers' awareness of alternative fruit species and cultivars as well as of new economic and consumption opportunities for fruits. University research to identify viable cultivars could expedite the otherwise trial-and-error approach currently in place, and even open the doors to legally sourcing desirable budstock or seedlings from outside the country if necessary. Researchers could also continue to monitor fruit production preferences, begin describing the actual economics of fruit production supplanting upland rice cultivation, and disseminate that information to those providing agroforestry resources to farmers. Ideally, the burden of training farmers and providing starter budstock and seedlings would fall primarily to government agencies; however, it seems even more crucial that these agencies focus on the establishment and maintenance of reliable transport networks so that farmers can sell what they are able to produce. Without such access to markets, fruit tree agroforestry efforts in the area may well be in vain (Freudenberger and Freudenberger 2002). Around Ranomafana NP, development organizations are currently the main advocates of agroforestry projects. As such, these organizations must continue to focus on aligning their strategies with farmer preferences in order to best support fruit production over upland rice cultivation.

\section{CONCLUSIONS}

Conservation managers may hesitate at the suggestion of promoting agroforestry systems focused on exotic fruits rather than on endemic species. Given the rate and extent of deforestation in southeastern Madagascar, though, supporting fruit tree agroforestry systems - even exotic ones - is an important beginning step in protecting and reestablishing a healthy, sustainable environment. This is especially true considering the alternative can be hillside cultivation of staples like rice using tavy. Encouraging farmers to adopt sustainable practices, then, involves managers' consideration of farmer needs and preferences in order to maintain buy-in and ensure the long-term success of those practices. In this case, managers are able to tailor their support of agroforestry systems based on a system's location by understanding that farmers have different planting patterns and preferences related to their distances from market networks on the road.

It is recommend that agroforestry nurseries in the study area propagate stocks based on the list provided above which is applicable to the entire study area, but prioritize efficiently transported fruits like coffee in projects far from roads. The nurseries must now decide how to address farmer preferences by producing appropriate numbers of seedlings and acquiring advantageous cultivars of each fruit.

\section{ACKNOWLEDGEMENTS}

We would like to acknowledge the support and input we received from Emile Rajeriarison and Jose Rabemiafara from the Association of Guides at Ranomafana NP; Peter Balasky and Pierrot Rahajanirina with Friends of Madagascar; Danielle Way, Randy Kramer, and Dean Urban at Duke's Nicholas School of the Environment; and our reviewers at Madagascar Conservation and Development.

\section{REFERENCES}

ANGAP (Association Nationale pour la Gestion des Aires Protégées). 2003. Madagascar protected area system management plan. ANGAP, Antananarivo.

Black, D. 1976. Partial justification of the Borda count. Public Choice 28, 1: $1-15$.

FAO (United Nations Food and Agriculture Organization). 2010. Global Forest Resources Assessment 2010: Global Tables. <http://www.fao.org/ forestry/fra/fra2010/en/> accessed 15 April 2012.

Freudenberger, M. S and Freudenberger, K. S. 2002. Contradictions in agricultural intensification and improved natural resource management: issues in the Fianarantsoa Forest Corridor of Madagascar. In: Natural Resources Management in African Agriculture: Understanding and Improving Current Practices. C. B. Barret and A. A. Aboud (eds.), pp 181-192. CABI Publishing, New York. 
Gezon, L. L. and Freed, B. Z. 1999. Agroforestry and conservation in northern Madagascar: hopes and hindrances. African Studies Quarterly 3, 2: 9-38.

Green, G. M. and Sussman, R. W. 1990. Deforestation history of the eastern rain forests of Madagascar from satellite images. Science 248,4952 : 212-215. (doi:10.1126/science.248.4952.212)

Harper, G. J., Steininger, M. K., Compton, J. T., Juhn, D. and Hawkins, F. 2007. Fifty years of deforestation and forest fragmentation in Madagascar. Environmental Conservation 34, 4: 325-333. (doi:10.1017/ S0376892907004262)

Holloway, L. 2004. Ecosystem restoration and rehabilitation in Madagascar Ecological Restoration 22, 2: 113-119. (doi:10.3368/er.22.2.113)

Jarosz, L. 1993. Defining and explaining tropical deforestation: shifting cultivation and population growth in colonial Madagascar. Economic Geography 69, 4: 366-379.

Kull, C. A. 2000. Deforestation, erosion, and fire: degradation myths in the environmental history of Madagascar. Environment and History 6, 4: 423-450.

Likert, R. 1932. A technique for the measurement of attitudes. Archives of Psychology 140: 1-55.

Ministère de I'Intérieur. 2011. Tableau faisant apparaître le nombre de population et le nombre des électeurs dans la commune rurale de Ranomafana. Région Vatovavy-Fitovanany, District D'Ifanadiana, Arrondissement Administratif de Ranomafana.

Nambena, S. M. 2003. Using geographic information systems to assess possibilities of expanding traditional agroforestry in slash-and-burn zones in Madagascar. Mountain Research and Development 23, 4: 329-333. (doi:10.1659/0276-4741(2003)023[0329:UGISTA]2.0.C0;2)

Peters, J. 1999. Understanding conflicts between people and parks at Ranomafana, Madagascar. Agriculture and Human Values 16, 1: 65-74. (doi:10.1023/A:1007572011454)

Randrianarijaona, P. 1983. The erosion of Madagascar. AMBIO 12, 6: 308-311.

Styger, E., Rakotoarimanana, J. E. M., Rabevohitra, R.and Fernandes, E.C.M. 1999. Indigenous fruit trees of Madagascar: potential components of agroforestry systems to improve human nutrition and restore biological diversity. Agroforestry Systems 46, 3: 289-310. (doi:10.1023/A:1006295530509)

Styger, E., Rakotondramasy, H. M., Pfeffer, M. J., Fernandes, E. C. M. and Bates, D. M. 2007. Influence of slash-and-burn farming practices on fallow succession and land degradation in the rainforest region of Madagascar. Agriculture, Ecosystems \& Environironment 119, 3-4: 257-269. (doi:10.1016/j.agee.2006.07.012)

Styger, E., Fernandes, E. C. M., Rakotondramasy, H. M. and Rajaobelinirina, E. 2009. Degrading uplands in the rainforest region of Madagascar: Fallow biomass, nutrient stocks, and soil nutrient availability. Agroforestry Systems 77, 2: 107-122. (doi:10.1007/s10457-009-9225-y)

Young, A. 1989. Agroforestry for soil conservation. CAB International, Wallingford, OxOn, UK.

\section{SUPPLEMENTARY MATERIAL.}

AVAILABLE ONLINE ONLY.

TABLE S1. Demographic breakdown of survey participants, which included a secondary school (CEG) class as one unit.

TABLE S2. Likert scale questions and results, showing the average response score for each statement.

TABLE S3. Frequency of mentioning "transportation" motivations for preferring to sell the top six fruits preferred to plant. All mentions of transportation come from farmers far from roads.

TABLE S4. Current fruit production in the two agroforestry nurseries established by FOM, in ranked order by number of seedlings produced.

TABLE S5. Final ranked recommendations for agroforestry production priorities.

TABLE S6. Survey questionnaire, in English and Malagasy, used to conduct guided interviews. 